\title{
POSITIONAL ACCURACY ASSESSMENT OF GOOGLEEARTH IN RIYADH
}

\author{
Ashraf Farah ${ }^{1}$ and Dafer Algarni ${ }^{2}$ \\ ${ }^{1}$ College of Engineering, Aswan University, Aswan, Egypt. \\ ${ }^{2}$ College of Engineering, King Saud University, Riyadh, KSA. \\ ashraf_farah@aswu.edu.eg
}

\begin{abstract}
Google Earth is a virtual globe, map and geographical information program that is controlled by Google corporation. It maps the Earth by the superimposition of images obtained from satellite imagery, aerial photography and GIS 3D globe. With millions of users all around the globe, GoogleEarth ${ }^{\circledR}$ has become the ultimate source of spatial data and information for private and public decision-support systems besides many types and forms of social interactions. Many users mostly in developing countries are also using it for surveying applications, the matter that raises questions about the positional accuracy of the Google Earth program. This research presents a small-scale assessment study of the positional accuracy of GoogleEarth ${ }^{\circledR}$ Imagery in Riyadh; capital of Kingdom of Saudi Arabia (KSA). The results show that the RMSE of the GoogleEarth imagery is $2.18 \mathrm{~m}$ and $1.51 \mathrm{~m}$ for the horizontal and height coordinates respectively.
\end{abstract}

Keywords: Positional accuracy, GoogleEarth, High-resolution imagery, Mapping, KSA

\section{INTRODUCTION}

The GoogleEarth ${ }^{\circledR}$ service (Google, 2013) is the most well-known and used internet service that provides free-of-charge access to the global collection of georeferenced satellite imagery. The service has many tools that allow users to not only extract spatial data but also to add their own content to the imagery, such as photographs and notes. GoogleEarth now hosts high-resolution ( 0.5 meter) imagery (McInnes et al., 2011)\& (Naji et al., 2013) allows human observers to readily discriminate between major natural land cover classes and to discern components of the human built environment, including; individual houses, industrial facilities, and roads.

There are domestic and international commercial satellite imagery companies that provide highresolution imagery that can be found in software tools like Google Earth and Bing Maps. Examples of these commercial companies and their employed satellites are:

-US based Digital Globe is currently operating three satellites: QuickBird, WorldView -1 and WorldView-2. (Digital Globe, 2014)

-US based GeoEye is currently operating three satellites: GeoEye-1, IKONOS and OrbView-2. (GeoEye, 2014)

-French based Spot Image is currently operating two satellites: SPOT 4 and SPOT 5. (SPOT, 2014)

-German based RapidEye is currently operating five satellites: RapidEye 1-5. (RapidEye, 2014)

-Netherlands Antilles based ImageSat is currently operating two satellites: EROS A and EROS B. (ImageSat, 2014)

However, it must be noted that GoogleEarth provides this service with a disclaimer that warns users about the quality of the data. Despite this warning, many individuals still refer to GoogleEarth ${ }^{\circledR}$ as a reliable and accurate data source. While inaccuracies in the GoogleEarth data are not expected to 
cause harm or damage in many cases, it can potentially cause problems if it is used for navigation purposes, or in technical tasks requiring high accuracy such as surveying and mapping applications. It worths referring to previous studies that assessed the positional accuracy of GoogleEarth such as (Potere, 2008), (Kazimierz BECEK et al., 2011), and (Naji et al., 2013).

(Potere, 2008) tested the Google Earth positional accuracy of 436 control points located in 109 cities worldwide. The study concluded that those control points had a positional accuracy of 39.7 meters RMSE (error magnitudes range from 0.4 to 171.6 meters). The accuracy of control points in more-developed countries is 24.1 meters RMSE, which is significantly more accurate than the control points in developing countries such as KSA (44.4 meters RMSE).

(Kazimierz BECEK et al., 2011) tested the Google Earth positional accuracy of more than 1900 control points located in five continents worldwide. The study concluded that the error could reach $1.5 \mathrm{~km}$ in some cases. (Naji et al., 2013) tested the Google Earth positional accuracy of 16 control points located in Khartoum state, Sudan. This was carried out by comparing Google Earth measured coordinates of control points with Global Positional System (GPS). Root Mean Square Errors (RMSE) for horizontal and height coordinates were found to be $1.59 \mathrm{~m} \& 1.7 \mathrm{~m}$ respectively.

This research presents an assessment study of the positional accuracy of GoogleEarth in Riyadh; KSA capital. The study involve two stages; the first stage is to investigate the horizontal accuracy of GoogleEarth by comparing the coordinates of nine stations derived from GoogleEarth with its (Static-Differential GPS) (Hoffmann-Wellenhof et al., 2008) high accuracy coordinates. The second stage is to investigate the vertical accuracy of GoogleEarth by comparing the orthometric heights of a $700 \mathrm{~m}$ track derived from GoogleEarth with its (Rapid Static-Differential GPS) (HoffmannWellenhof et al., 2008) high accuracy elevations.

\section{TEST STUDY}

Firstly, to investigate the horizontal accuracy of GoogleEarth, nine stations were located in the campus of King Saud University (KSU, 2013), Riyadh. The horizontal coordinates of those stations whose considered the truth were evaluated using differential static-GPS technique. Dual frequency GPS observations were collected at each station using LEICA-SR530 receiver for 30 minutes with 1 sec recording interval, $10^{\circ}$ mask angle. The collected observations were processed using Leica SKIPro software. The horizontal positional errors for tested stations evaluated from differential staticGPS are shown in Table 1. The GoogleEarth horizontal Coordinates for tested stations were estimated, and compared to the truth coordinates of differential static-GPS.

Table 1: The horizontal positional errors for tested stations evaluated from differential static-GPS.

\begin{tabular}{|c|c|c|}
\hline Station no. & Latitude error $(\mathrm{m})$ & Longitude error $(\mathrm{m})$ \\
\hline 1 & 0.0005 & 0.0005 \\
\hline 2 & 0.0003 & 0.0003 \\
\hline 3 & 0.0009 & 0.0005 \\
\hline 4 & 0.0002 & 0.0002 \\
\hline 5 & 0.0002 & 0.0002 \\
\hline 6 & 0.0007 & 0.0007 \\
\hline 7 & 0.0007 & 0.0008 \\
\hline 8 & 0.0003 & 0.0003 \\
\hline 9 & 0.0006 & 0.0004 \\
\hline
\end{tabular}

Secondly, to investigate the vertical accuracy of GoogleEarth, a $700 \mathrm{~m}$ track was located just outside the campus of KSU, Riyadh. The tested track was divided into 15 stations with $50 \mathrm{~m}$ separation distance. The orthometric height of those stations whose considered the truth were evaluated using differential Rapid static-GPS technique. Dual frequency GPS observations were collected at each station using LEICA-SR530 receiver for 10 minutes with $1 \mathrm{sec}$ recording interval, $10^{\circ}$ mask angle. The collected observations were processed using Leica SKI-Pro software. The height positional 
errors for tested stations evaluated from differential Rapid static-GPS are shown in Table 2. The GoogleEarth orthometric heights for tested 15 stations were estimated and compared to the truth heights of differential Rapid Static-GPS.

Table 2: The height positional errors for tested stations evaluated from differential Rapid static-GPS.

\begin{tabular}{|c|c|}
\hline Station no. & height error $(\mathrm{m})$ \\
\hline 1 & 0.0026 \\
\hline 2 & 0.0011 \\
\hline 3 & 0.0009 \\
\hline 4 & 0.0013 \\
\hline 5 & 0.0014 \\
\hline 6 & 0.0011 \\
\hline 7 & 0.0011 \\
\hline 8 & 0.0010 \\
\hline 9 & 0.0010 \\
\hline 10 & 0.0014 \\
\hline 11 & 0.0009 \\
\hline 12 & 0.0015 \\
\hline 13 & 0.0016 \\
\hline 14 & 0.0253 \\
\hline 15 & 0.0019 \\
\hline
\end{tabular}

\section{RESULTS, ANALYSIS AND DISCUSSION}

Table 3 presents the outcome of the assessment of the horizontal accuracy of GoogleEarth where the GoogleEarth horizontal Coordinates for the tested nine stations were compared with its truth horizontal Coordinates (differential static-GPS) and the horizontal shifts were computed. Table 4 presents statistical analysis for the results of this test.

Table 3: The results of the assessment of the horizontal accuracy of GoogleEarth.

\begin{tabular}{|c|c|c|c|c|c|c|c|}
\hline \multirow{2}{*}{$\begin{array}{c}\text { Station } \\
\text { ID. }\end{array}$} & \multicolumn{2}{|l|}{$\begin{array}{l}\text { GPS static-differential } \\
\text { Coordinates }(1)\end{array}$} & \multicolumn{2}{l|}{$\begin{array}{l}\text { Google Earth } \\
\text { Coordinates }(2)\end{array}$} & \multicolumn{2}{|c|}{$\begin{array}{c}\text { Coordinates } \\
\text { Diff. } \\
(1-2)\end{array}$} & $\begin{array}{c}\text { Horizontal } \\
\text { Shift }(\mathrm{m}) \\
\left(\Delta \mathrm{N}^{2}+\Delta \mathrm{E}^{2}\right)^{0.5}\end{array}$ \\
\cline { 2 - 7 } & $\mathrm{N}(\mathrm{m})$ & $\mathrm{E}(\mathrm{m})$ & $\mathrm{N}(\mathrm{m})$ & $\mathrm{E}(\mathrm{m})$ & $\Delta \mathrm{N}(\mathrm{m})$ & $\Delta \mathrm{E}(\mathrm{m})$ & \\
\hline 1 & 2733870.70 & 664641.60 & 2733864.00 & 664643.00 & 6.70 & -1.40 & 6.84 \\
\hline 2 & 2734301.80 & 665046.60 & 2734295.00 & 665047.00 & 6.80 & -0.40 & 6.81 \\
\hline 3 & 2735107.90 & 665373.60 & 2735100.55 & 665376.25 & 7.35 & -2.65 & 7.81 \\
\hline 4 & 2735531.50 & 663465.90 & 2735525.76 & 663466.75 & 5.74 & -0.85 & 5.80 \\
\hline 5 & 2735517.60 & 662974.10 & 2735511.83 & 662974.86 & 5.77 & -0.76 & 5.82 \\
\hline 6 & 2734063.10 & 663691.90 & 2734057.60 & 663693.61 & 5.50 & -1.71 & 5.76 \\
\hline 7 & 2737347.00 & 664197.10 & 2737341.51 & 664197.45 & 5.49 & -0.35 & 5.50 \\
\hline 8 & 2735887.00 & 664012.30 & 2735874.50 & 664011.99 & 12.50 & 0.31 & 12.50 \\
\hline 9 & 2734748.40 & 663919.20 & 2734744.25 & 663921.42 & 4.15 & -2.22 & 4.71 \\
\hline
\end{tabular}


Table 4: Statistical analysis for the assessment of the horizontal accuracy of GoogleEarth study.

\begin{tabular}{|l|l|l|l|l|}
\hline $\begin{array}{l}\text { Average } \\
\text { horizontal Shift }(\mathrm{m})\end{array}$ & $\begin{array}{l}\text { Maximum } \\
\text { horizontal } \\
\text { Shift }(\mathrm{m})\end{array}$ & $\begin{array}{l}\text { Minimum } \\
\text { horizontal } \\
\text { Shift }(\mathrm{m})\end{array}$ & $\begin{array}{l}\text { Standard deviation } \\
\text { of horizontal Shift } \\
(\mathrm{m})\end{array}$ & $\begin{array}{l}\text { Root Mean Square Error } \\
\text { (RMSE) of horizontal Shift }(\mathrm{m})\end{array}$ \\
\hline 6.84 & 12.50 & 4.71 & 2.31 & 2.18 \\
\hline
\end{tabular}

Table 5 presents the outcome of the assessment of the vertical accuracy of GoogleEarth where the GoogleEarth orthometric height for the tested 15 stations were compared with its truth orthometric heights (differential Rapid Static-GPS) and the height Shifts were computed. Table 6 presents statistical analysis for the results of this test. Fig. 1 presents graphical presentation for the study outcome.

Table 5: The results of the assessment of the vertical accuracy of GoogleEarth

\begin{tabular}{|c|c|c|c|}
\hline $\begin{array}{c}\text { Station } \\
\text { Distance (m) }\end{array}$ & $\begin{array}{c}\text { Orthometric } \\
\text { height by Rapid } \\
\text { Static-differential } \\
\text { GPS (m) }\end{array}$ & $\begin{array}{c}\text { Orthometric } \\
\text { height by } \\
\text { GoogleEarth (m) }\end{array}$ & $\begin{array}{c}\text { Orthometric } \\
\text { Height } \\
\text { Difference(m) }\end{array}$ \\
\hline 0 & 635.93 & 637.00 & -1.07 \\
\hline 50 & 636.66 & 638.00 & -1.34 \\
\hline 100 & 637.44 & 639.00 & -1.56 \\
\hline 150 & 638.41 & 639.00 & -0.59 \\
\hline 200 & 639.56 & 640.00 & -0.44 \\
\hline 250 & 641.27 & 641.00 & 0.27 \\
\hline 300 & 643.79 & 643.00 & 0.79 \\
\hline 350 & 646.73 & 645.00 & 1.73 \\
\hline 400 & 645.65 & 645.00 & 0.65 \\
\hline 450 & 645.66 & 643.00 & 2.66 \\
\hline 500 & 643.82 & 644.00 & -0.18 \\
\hline 550 & 642.78 & 645.00 & -2.22 \\
\hline 600 & 642.67 & 645.00 & -2.33 \\
\hline 650 & 642.21 & 644.00 & -1.79 \\
\hline 700 & 642.89 & 642.00 & 0.89 \\
\hline & & & \\
\hline
\end{tabular}

Table 6: statistical analysis for the assessment of the vertical accuracy of GoogleEarth study.

\begin{tabular}{|l|l|l|l|l|}
\hline $\begin{array}{l}\text { Average } \\
\text { orthometric } \\
\text { height Shift }(\mathrm{m})\end{array}$ & $\begin{array}{l}\text { Maximum } \\
\text { orthometric } \\
\text { height Shift }(\mathrm{m})\end{array}$ & $\begin{array}{l}\text { Minimum } \\
\text { orthometric } \\
\text { height Shift }(\mathrm{m})\end{array}$ & $\begin{array}{l}\text { Standard deviation } \\
\text { of orthometric } \\
\text { height Shift }(\mathrm{m})\end{array}$ & $\begin{array}{l}\text { Root Mean Square Error } \\
\text { (RMSE) of orthometric } \\
\text { height Shift }(\mathrm{m})\end{array}$ \\
\hline-0.30 & 2.66 & -2.33 & 1.47 & 1.51 \\
\hline
\end{tabular}




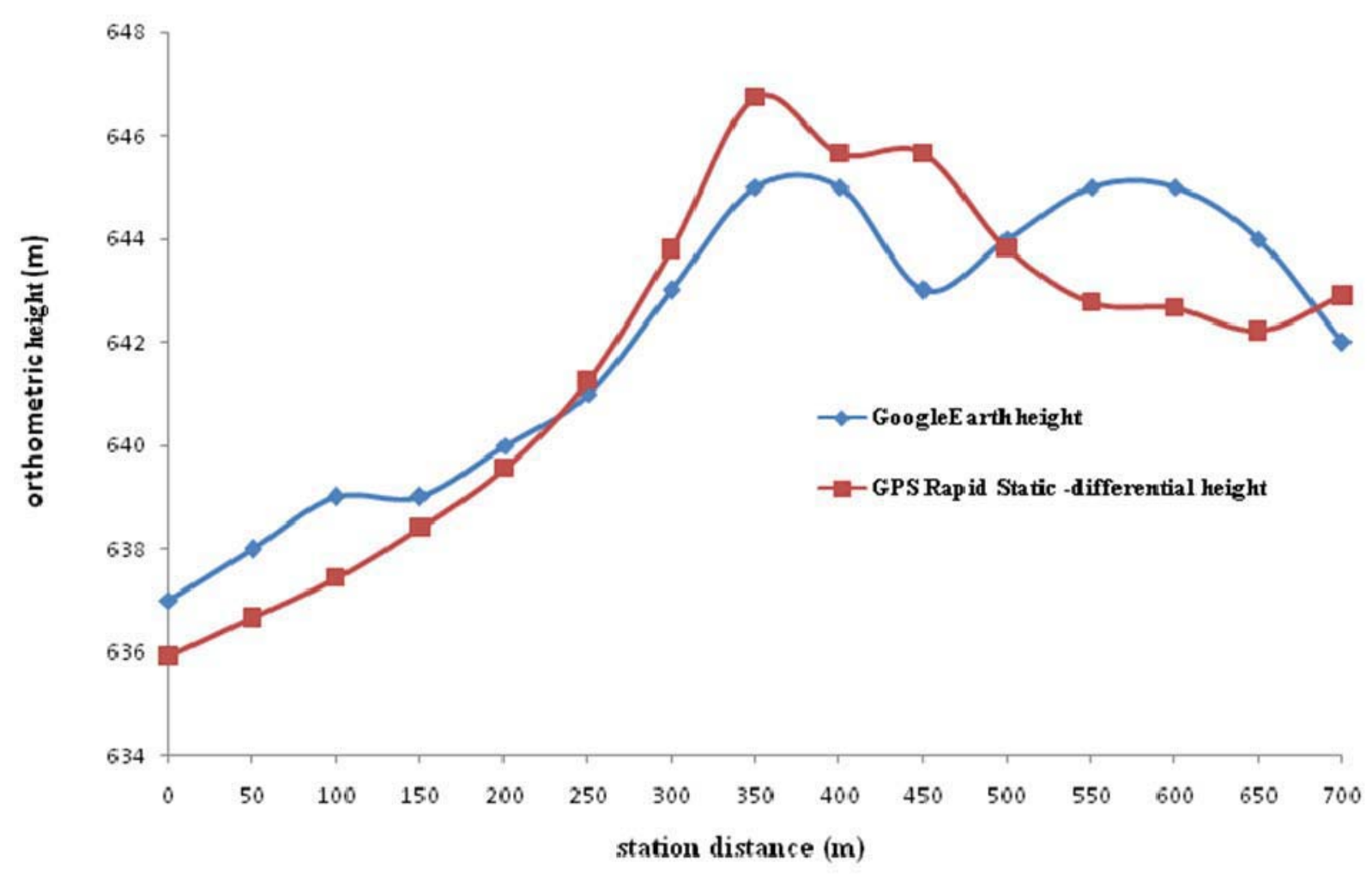

Fig. 1: Orthometric height from GoogleE arth softw are and GPS Rapid-Static differ ential technique.

Concerning the horizontal Accuracy of GoogleEarth, it appears from Table 4 that GoogleEarth images give mean horizontal shift of about $6.84 \mathrm{~m}$ with smaller errors in east direction rather than the north direction. The max. horizontal shift was $12.50 \mathrm{~m}$ where the minimum shift was $4.71 \mathrm{~m}$. The RMSE is found to be $2.18 \mathrm{~m}$.

Concerning the vertical Accuracy of GoogleEarth, it appears from Table 6 that GoogleEarth images give mean height error of about $0.30 \mathrm{~m}$. The max. orthometric height error was $2.66 \mathrm{~m}$ where the minimum error was similar about $-2.33 \mathrm{~m}$. The RMSE is found to be $1.51 \mathrm{~m}$.

\section{CONCLUSIONS}

This research presents an assessment small-scale study of the positional accuracy of GoogleEarth in Riyadh; KSA capital where the performance of GoogleEarth was compared with GPS static differential. The GoogleEarth horizontal Error was in the range of $(4.71 \mathrm{~m}$ to $12.50 \mathrm{~m})$ with a mean value of $6.84 \mathrm{~m}$ and RMSE of $2.18 \mathrm{~m}$. The GoogleEarth vertical Error was in the range of $(-2.33 \mathrm{~m}$ to $2.66 \mathrm{~m}$ ) with a mean value of $0.30 \mathrm{~m}$ and RMSE of $1.51 \mathrm{~m}$. Those findings agreed with previous studies in nearby areas such as Sudan (Naji el al., 2013). Those findings are valid in the place of study and should not be applicable elsewhere. Other studies are needed prior to conclude certain accuracy elsewhere. Finally, it seems that the exterior orientation of the GoogleEarth imagery is reasonable at the present time and might be able to improve in the near future. GoogleEarth's current accuracy enables surveyors to have topographic information and produce contour maps with 1:50,000 scale and smaller.

\section{REFERENCES}

Digital Globe (2014). (http://www.digitalglobe.com/resources/product-data-sheets) Accessed $(28 / 3 / 2014)$.

GeoEye (2014). (http://www.satimagingcorp.com/satellite-sensors/geoeye-1.html) Accessed $(28 / 3 / 2014)$. 
Google (2013). Google Earth service web page. (http://www.google.com/earth/index.html) Accessed $(20 / 6 / 2013)$.

Hoffmann-Wellenhof, B., Lichtenegger, H. and Elmar Wasle (2008). GNSS - Global Navigation Satellite Systems: GPS, GLONASS, Galileo, and more. Springer-Verlag, Wien, New York.

ImageSat (2014). (http://www.imagesatintl.com/) Accessed (28/3/2014).

Kazimierz BECEK and KHAIRUNNISA Ibrahim, Brunei Darussalam (2011). On the Positional Accuracy of the GoogleEarth ${ }^{\circledR}$ Imagery. FIG Working Week 2011 (Bridging the Gap between Cultures), Marrakech, Morocco, 18-22 May 2011.

KSU (2013). King Saud University web page. (http://www.ksu.edu.sa). Accessed (20/6/2013).

McInnes J., O.Vigiak and A.M. Roberts (2011).Using Google Earth to map gully extent in the West

Gippsland region (Victoria, Australia). 19th International Congress on Modelling and Simulation, Perth, Australia, 12-16 December 2011.

Nagi Zomrawi Mohammed, Ahmed Ghazi and Hussam Eldin Mustafa (2013). Positional Accuracy Testing of Google Earth. International Journal of Multidisciplinary Sciences and Engineering, Vol. 4, No. 6, July 2013.

Potere, D. (2008). Horizontal Positional Accuracy of Google Earth's High- Resolution Imagery Archive. Sensors 2008, 8, 7973-7981; DOI: 10.3390/s8127973.

RapidEye (2014). (http://blackbridge.com/rapideye/) Accessed (28/3/2014).

SPOT (2014). (http://www.astrium-geo.com/) Accessed (28/3/2014).

Received: 2014-02-18,

Reviewed: 2014-05-19,

Accepted: 2014-05-23. 